of smoke toxicity - which has pitted the plastics industry against the steel industry over the use of plastics in electrical conduit and other building applications - the centre is "the only credible source of technical information", according to the National Fire Protection Association, a non-profit organization that writes widely-used model fire codes.

Even the plastics industry, which had lodged strong objections to the centre's work on smoke toxicity, issued a statement from its trade association, the Society for Plastics Industry, asking for "serious reconsideration" of the decision to eliminate the centre.

Just why the Administration decided to single out fire research is unclear. Dr Fred Clark, former director of the centre and now a private consultant, said he doubted that concern over the projected $\$ 200,000$ million federal deficit could really have been the issue. "All the Reagan Administration has to do is find $\mathbf{4 0 , 0 0 0}$ more issues like the Center for Fire Research and they can balance the budget', he said.

NBS is also facing the loss of its Center for Building Technology in the 1984 budget, a 70 per cent cut in its Institute for Computer Science and Technology (which is developing compatibility standards for the computer industry) and substantial cuts in the Standard Reference Materials and Measurements Assurance Programs, with the funding to be made up by increased "user fees".
Saleroom news

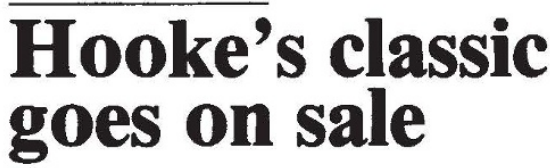

A FIRST edition of Robert Hooke's Micrographia, a work which heralded the birth of scientific microscopy, is to be auctioned this week at Christie's saleroom in London. The auctioneers estimate that the volume will fetch between $£ 3,000$ and $£ 4,000$, which seems a moderate price for such a rare item.

The full title of Hooke's historic work, first published in 1665, is impressive: Micrographia, or some physiological descriptions of minute bodies made by magnifying glasses with observations and enquiries thereupon. It was the first book in English devoted to microscopy and it is enriched by many superb copperplate illustrations in Hooke's own hand. Two drawings in particular - showing a flea and a louse enlarged to about 20 inches in length - created considerable interest when the book was published.

Unfortunately, Hooke's original microscope has not survived but from his extremely clear drawing and description it is seen to have possessed a screw focusing arrangement, and a ball and socket joint providing inclination of the body tube. The stage was an innovation, as was the means of illumination.

Hooke may be remembered in some

\title{
Women in science in the United Kingdom
}

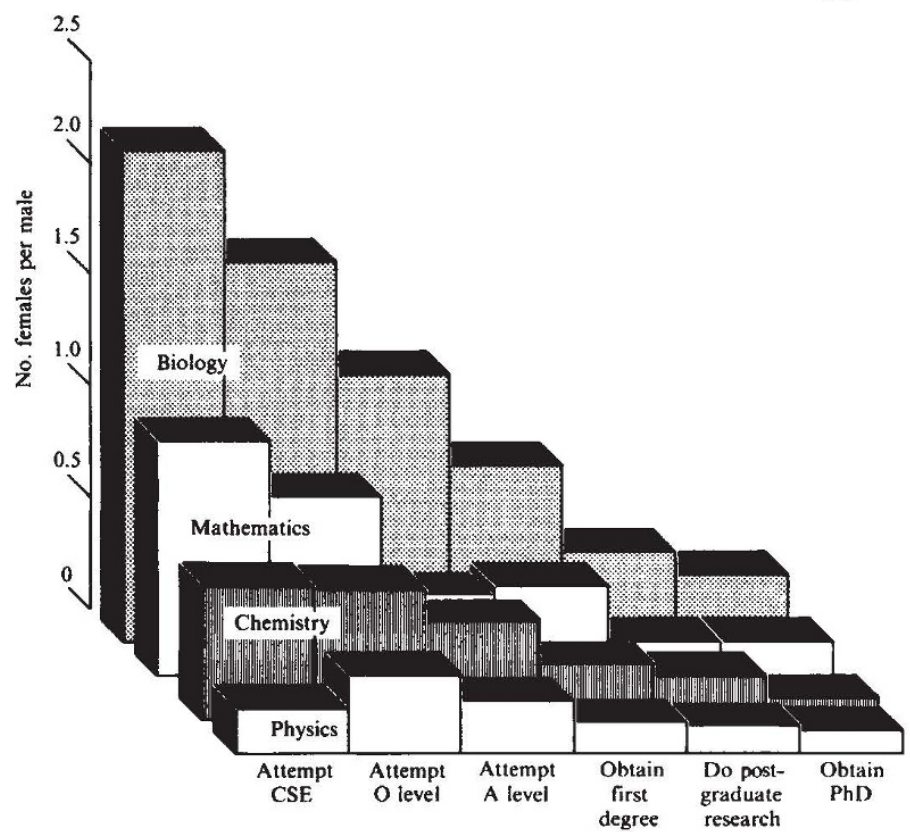

LOOKING at the number of females per male studying individual science subjects at various levels of the education system in England and Wales, it emerges that there are more males than females taking almost every pure science subject at all levels. Only elementary biology is studied by more girls than boys, and even this situation is reversed at degree level. Overall, the same number of girls as boys study science up to the age of 16 , after which female representation progressively lessens until, at the postgraduate level, only one in six of those who obtain a PhD is female.

Source: Institute of Physics.

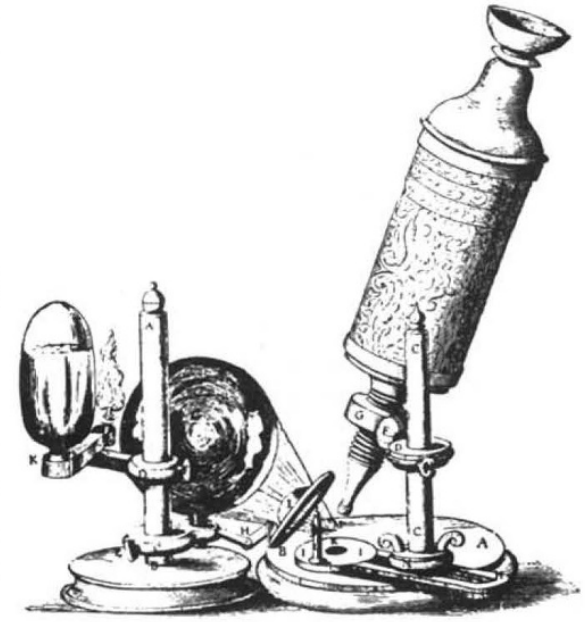

Hooke's microscope, as shown in Micrographia.

circles for his microscopical observations but today his name is more likely to be associated with his law of elasticity or with his work on the Boylean air-pump. His many other inventions and discoveries seem, for the most part, to be forgotten. Who for instance remembers that it was Hooke who invented the marine barometer and the spirit level, and discovered the phenomenon of diffraction?

He was involved in such diverse matters as the manufacture of artificial fibres, the building of a steam engine and a theory of evolution. And after the Great Fire of London he still found time to lay before the Royal Society a model for the re-building of the City. He was by some accounts first with a Gregorian-type reflecting telescope, a reflecting quadrant and a method of regulating watches by a balance spring.

Yet despite his many contributions to science there appears to have been little love lost between him and many of his fellow scientists. It is true that as a Fellow and later as Secretary of the Royal Society he was recognized as a natural philosopher of considerable standing. Yet unsubstantiated charges were made, and repeated ad nauseam, claiming that not only did he set too high a value on much of his work, but also that he claimed as his own the inventions of others.

At least some of the bitterness may have stemmed from Hooke's strenuous opposition to Isaac Newton's hypothesis on the different refrangibility of light rays. It was suggested, somewhat uncharitably, that his opposition had been prompted by the rising reputation of this new philosopher working in a field that Hooke looked on as his own. Hooke was subjected to a barrage of abuse, and to hear himself described as "envious, suspicious and of a natural peevishness of character" did not improve his relationship with his fellow scientists.

But whatever may be said of his disposition, he stands out as a leading personality of the seventeenth century and one of the great inventive minds of all time.

Arthur Frank 